\title{
ESTUDO DO COMPORTAMENTO DE QUEIJO MUSSARELA DURANTE ARMAZENAMENTO REFRIGERADO
}

\section{Study of Mozzarella cheese behavior during refrigerated storage}

\author{
Thamara Evangelista Silva ${ }^{l}$, Thamiris Evangelista Silva ${ }^{l}$, \\ Lismaíra Gonçalves Caixeta Garcial,Priscila Alonso dos Santos ${ }^{{ }^{*}}$
}

\begin{abstract}
RESUMO
Este estudo foi realizado para avaliar o comportamento do queijo Mussarela de alta umidade ao longo de 60 dias de armazenamento a $7^{\circ} \mathrm{C}$ em estufa tipo BOD quanto à qualidade microbiológica, composição físico-química, propriedades funcionais e perfil de textura. Os queijos foram adquiridos em laticínio do município de Rio Verde, GO. As análises foram realizadas durante 60 dias com intervalos de 20 dias entre as análises. Para avaliar se as mudanças ocorridas durante o tempo de armazenamento foram significativas, foi realizada a análise de variância e as médias dos diferentes dias de armazenamento foram comparadas pelo Teste de Tukey a 95\% de confiança. Os resultados apontaram qualidade higiênico-sanitária na produção dos queijos. A composição físico-química foi influenciada pelo tempo apenas com relação ao conteúdo de $\mathrm{pH}$ e proteína, porém os mesmos apresentaram-se conforme estudos já realizados. Já as propriedades funcionais dos queijos analisados sofreram influência do tempo de armazenamento, apenas o teor de óleo livre se manteve estável. A cor dos queijos apresentou valores com tendência a coloração amarela durante todo o período de armazenamento. À medida que ocorreu o aumento da proteólise primária e secundária, houve também o aumento na capacidade de derretimento e alterações nos parâmetros de textura. O queijo Mussarela apresentou-se próprio para o consumo com período de armazenamento de 60 dias a $7{ }^{\circ} \mathrm{C}$, sendo que as mudanças ocorridas são aceitáveis e requeridas, pelo fato de os queijos serem comumente utilizados em pizzas.
\end{abstract}

Palavras-chave: microrganismos psicrotróficos, proteólise, shelflife.

1 Instituto Federal Goiano, Campus Rio Verde, Rua Sul Goiana, Km 01, Zona Rural, 75901-970, Rio Verde, GO, Brasil. E-mail: priscila.santos@ifgoiano.edu.br

* Autor para correspondência. 


\begin{abstract}
This study was carried out to evaluate the behavior of high moisture Mozzarella cheese during 60 days of storage at $7{ }^{\circ} \mathrm{C}$ in BOD incubator for microbiological quality, physicochemical composition, functional properties, and texture profile. The cheeses were purchased in a dairy industry from the city of Rio Verde, GO. The study was performed for 60 days at 20 days intervals between analysis. In order to evaluate if the changes occurred during storage time were significant, the analysis of variance was performed, and the means of the different storage days were compared by the Tukey test at $95 \%$ confidence. The results indicated hygienic-sanitary quality in the production of cheeses. The physicochemical composition was influenced by time only in the $\mathrm{pH}$ values and protein content; however, they were in accordancewith studies already performed. The functional properties of the cheeses were influenced by the storage time, only the free oil content remained stable. The color analysis of the cheeses showed values tending to yellow coloration throughout the storage period. As the primary and secondary proteolysis increased, there was also an increase in the melting capacity and changes in the texture parameters. Mozzarella cheese was suitable for consumption with a storage period of 60 days at $7{ }^{\circ} \mathrm{C}$, and the changes that have occurred are acceptable and required because this cheese is commonly used in pizzas.
\end{abstract}

Keywords: psychrotrophic microorganisms, proteolysis, shelf life.

\section{INTRODUÇÃO}

Os queijos são um sistema complexo composto principalmente de proteínas, gorduras, minerais e água, obtidos por mistura, diferentes aquecimento e maturação, além dos coagulantes e sais (OLIVEIRA, 2012). Durante a vida útil do queijo Mussarela ocorre uma série de processos físico-químicos, bioquímicos e microbiológicos. Estes processos modificam a massa do queijo em sua composição, estrutura, consistência, sabor e cor (PAULA et al., 2009).

Os principais microrganismos responsáveis pela deterioração e instabilidade de queijos Mussarela são coliformes (CANTONI et al., 2006) e psicrotróficos proteolíticos (BARUZZI et al., 2012). As bactérias psicrotróficas são capazes de produzir enzimas extracelulares, tais como proteases, lipases e lecitinases, responsáveis por alterações bioquímicas no queijo, como proteólise, e sua produção aumenta em função das condições de armazenagem (JONGHE et al., 2011).

A proteólise consiste na desestabilização das micelas de caseína através da liberação de peptídeos e aminoácidos que se submetem a um processo catabólico, formando-se assim outros compostos voláteis tais como aminas, ácidos, os tióis, os ésteres e outros (WOLF et al., 2010; GARCIA et al., 2012; STEELE et al., 2013). O aumento do índice de maturação também se dá devido ao coagulante residual e plasmina causando proteólise no queijo Mussarela (OLIVARES et al., 2012).

A qualidade microbiológica e a composição físico-química de queijo Mussarela de alta umidade são fortemente afetadas pelo tempo de estocagem (RICCIARDI et al., 2015). As características funcionais são importantes devido a utilização do queijo Mussarela como um ingrediente em pizza, as mesmas são determinadas principalmente pela ação de quebra da matriz proteica. A 
excessiva ação proteolítica resulta em problemas de fatiamento porque o corpo do queijo fica muito macio, perda progressiva da elasticidade, maior derretimento, porém tende a aumentar a intensidade à liberação de gordura dando origem ao oilling off (óleo livre) (KINDSTEDT; FOX, 1993). Quanto mais caseína estiver intacta no queijo maior é a dificuldade de fatiar ou picar, pois o queijo fica mais quebradiço, apresentando massa firme com pouca elasticidade, baixa capacidade de derretimento e textura rígida (ROIG et al., 2003).

A textura da Mussarela é influenciada pela composição química inicial do queijo e as condições de processamento utilizadas durante a fabricação (REN et al, 2013). É importante ter um controle adequado dos parâmetros que afetam a textura, pois além de influenciar diretamente a qualidade e satisfação do consumidor, torna-se capaz de produzir desde queijos mais macios até queijos mais duros com diferentes tipos de consumos e mercados consumidores (PIAZZON-GOMES et al., 2010).

Entender os fatores que determinam as características do queijo Mussarela é importante para que os fabricantes tenham conhecimento das alterações sucedidas durante a vida útil do queijo mantido sob refrigeração, para melhor atender as predileções de seus clientes. O objetivo através deste trabalho foi compreender o comportamento do queijo Mussarela de alta umidade ao longo de 60 dias de armazenamento a $7{ }^{\circ} \mathrm{C}$ em estufa tipo $\mathrm{BOD}$, quanto a qualidade microbiológica, composição físico-química, propriedades funcionais e perfil de textura.

\section{MATERIAL E MÉTODOS}

Os queijos Mussarela foram obtidos em uma indústria no município de Rio Verde, estado de Goiás. Foram adquiridas 5 barras de queijos, de lotes diferentes (representando as repetições), cada barra de queijo pesava $4 \mathrm{~kg}$, sendo assim as mesmas foram dividas assepticamente em quatro partes, referentes aos dias de análise, embaladas a vácuo em sacos de polietileno e armazenadas a $7{ }^{\circ} \mathrm{C}$ em estufa tipo BOD (LimaTec LT 320). As amostras foram analisadas durante dois meses, com intervalos de 20 dias entre as análises, iniciando-se no dia 0 (dias 0, 20, 40 e 60 de armazenamento). As amostras de queijo foram analisadas quanto às análises microbiológicas, físico-químicas e funcionais.

\section{Análises microbiológicas}

\section{Preparo das amostras}

Alíquotas de $25 \mathrm{~g}$ de queijo Mussarela foram assepticamente pesadas em sacos plásticos estéreis e homogeneizadas com $225 \mathrm{~mL}$ de água peptonada $0,1 \%$ esterilizada durante 1 minuto em homogeneizador tipo stomacher (Marconi LE4S). Diluições decimais a partir da diluição $10^{-1}$ foram preparadas em tubos contendo $9,0 \mathrm{~mL}$ de água peptonada $0,1 \%$.

\section{Coliformes totais e termotolerantes}

Para a enumeração de coliformes totais e termotolerantes foi utilizada a técnica do Número Mais Provável (NMP). A análise presuntiva de coliformes foi realizada em Caldo Lauril Sulfato de Sódio, com incubação por 48 horas a $35^{\circ} \mathrm{C}$. Foi realizada também a enumeração de coliformes totais em Caldo Lactosado Bile Verde Brilhante, com incubação a $35^{\circ} \mathrm{C}$ por 24 a 48 horas. A enumeração de coliformes termotolerantes foi feita em Caldo Escherichia coli, com incubação a $45,5{ }^{\circ} \mathrm{C}$ por 24 horas. Utilizou-se a tabela NMP para calcular o "Número Mais Provável" de coliformes termotolerantes por grama de alimento (ABNT, 1991). 


\section{Microrganismos psicrotróficos e psicrotróficos proteolíticos}

Para contagem padrão de microrganismos psicrotróficos adicionou-se $1 \mathrm{~mL}$ das sucessivas diluições,em placas de Petri (15x100) esterilizadas e em seguida adicionou-se ágar-padrão para contagem (Plate Count Agar - PCA) (APHA, 2001). Após a solidificação do ágar em temperatura ambiente $\left( \pm 25^{\circ} \mathrm{C}\right)$ as placas foram incubadas invertidas durante 10 dias à $7{ }^{\circ} \mathrm{C}$ e depois realizada a contagem (MARSHALL, 1992).

Para contagem padrão de microrganismos psicrotróficos proteolíticos foi adicionado $0,1 \mathrm{~mL}$ das diluições em placas de Petri $(15 \times 100)$ esterilizadas e contendo ágar-leite (ágar-padrão acrescido de 10\% de leite em pó desnatado reconstituído a $10 \%$, preparado recentemente, fundido e resfriado a $45^{\circ} \mathrm{C}$ ). As placas foram incubadas durante 72 horas à $21{ }^{\circ} \mathrm{C}$ e depois realizado a contagem (MARSHALL, 1992). As colônias de microrganismos proteolíticos apresentam-se rodeadas por uma zona clara, o que é resultado da conversão da caseína em compostos nitrogenados solúveis. Como o meio é opaco, utiliza-se um precipitante químico (ácido acético $10 \%$ ) para detectar a proteólise e, assim, verificar se as zonas claras são causadas por proteólise ou pela formação de ácidos devida à fermentação de carboidratos. Foi efetuada a contagem apenas das colônias que possuem halo transparente ao seu redor (SANTOS, 2008).

\section{Análises físico-químicas}

A determinação do $\mathrm{pH}$ foi realizada utilizando-se potenciômetro digital (LUCA 210P). O aparelho foi calibrado com solução tampão de pH 4,0 e 7,0, em seguida, realizouse a leitura direta do $\mathrm{pH}$ com imersão do eletrodo no béquer, contendo a amostra, segundo metodologia proposta pela AOAC
(2012). A acidez total titulável foi determinada pela titulação com solução de hidróxido de sódio $(\mathrm{NaOH}) 0,1 \mathrm{~N}$, usando como indicador a fenolftaleína $1 \%$, conforme a AOAC (2012).

O teor de umidade foi determinado conforme técnica descrita pela Association of Official Analytical Chemists (AOAC, 2012); cinzas, determinada por incineração em mufla a $550{ }^{\circ} \mathrm{C}$ (AOAC, 2012); cloretos foi determinado utilizando o resíduo da análise de cinzas por titulação com nitrato de prata $0,1 \mathrm{~N}$ (BRASIL, 2006); proteínas segundo o método de micro-Kjeldahl (AOAC, 2012); lipídeos totais pelo método de Gerber (BRASIL, 2006); gordura no extrato seco (GES) por meio da razão percentual entre o teor de gordura e o teor de extrato seco total (BRASIL, 2006).

O índice de extensão da proteólise (IEP) e o índice de profundidade da proteólise (IPP) dos queijos foram calculados usando o nitrogênio total, nitrogênio solúvel em pH 4,6, e nitrogênio solúvel em ácido tricloroacético (TCA) a 12\% (IPP) (AOAC, 2012). Todas as análises foram realizadas em triplicata durante os dias de armazenamento.

\section{Propriedades funcionais}

A capacidade de derretimento dos queijos Mussarela foi determinada através da adaptação do método de Schreibers, para queijo processado, descrito por (KOSIKOWSKI; MISTRY, 1997). A adaptação consistiu em fatiar a peça de queijo em $7 \mathrm{~mm}$ e com o auxílio de um cortador retirar estas fatias em cilindro de $36 \mathrm{~mm}$ de diâmetro. As placas já estavam devidamente marcadas com quatro linhas dispostas em ângulos de $45^{\circ}$. O diâmetro de cada amostra foi calculado como a média dos diâmetros, nas quatro direções, medidos antes e após o derretimento por 7 minutos em estufa (Nova Ética 400/ND) a $107{ }^{\circ} \mathrm{C}$. A partir dos diâmetros médios, foi 
calculada a porcentagem de derretimento das fatias de queijo, por meio da equação 1 .

$\%$ de derretimento $=\frac{\left[\mathrm{D}_{\text {final }}-\mathrm{D}_{\text {inicial }}\right]}{\left.\mathrm{D}_{\text {inicial }}\right]}$

onde, $\mathrm{D}_{\text {inicial }}$ é o diâmetro inicial e $\mathrm{D}_{\text {final }}$ é o diâmetro final.

A liberação de óleo livre foi avaliada em duas repetições pelo método de Gerber modificado, conforme Kindstedt; Fox (1991). Os resultados foram expressos em percentual de óleo livre a partir da média de gordura obtida na escala do butirômetro.

A determinação da cor foi realizada por meio da leitura de três parâmetros definidos pelo sistema CIEL*a*b*. Os parâmetros L*, $a^{*} e^{*}$ foram fornecidos pelo colorímetro (Hunterlab, Color Flex EZ Spectrophotometer), no qual $\mathrm{L}^{*}$ define a luminosidade $\left(\mathrm{L}^{*}=\right.$ 0 preto e $\mathrm{L}^{*}=100$ branco) e $\mathrm{a}^{*} \mathrm{e} \mathrm{b}$ definem a cromaticidade $\left(+\mathrm{a}^{*}=\right.$ vermelho $\mathrm{e}-\mathrm{a}^{*}=$ verde, $+b^{*}=$ amarelo $\mathrm{e}-\mathrm{b}^{*}=$ azul). Com as determinações das coordenadas $\mathrm{a}^{*} \mathrm{e} \mathrm{b}^{*}$, foram calculados os parâmetros de cromaticidade (Equação 2) e o ângulo Hue (Equação 3). As amostras foram cortadas em $2 \mathrm{~cm}^{3}$, a leitura foi realizada com duas repetições em hexaplicata.

$$
\begin{aligned}
& C=\sqrt{a^{*^{2}}+b^{*^{2}}} \\
& { }^{\circ} \text { Hue }=\operatorname{arctg}\left(\frac{b^{*}}{a^{*}}\right)
\end{aligned}
$$

Ensaios do perfil de textura (TPA) foram realizados utilizando um analisador de textura (CT3 TextureAnalyzer - Brookfield), equipado com uma célula de carga de $25 \mathrm{~kg}$. As amostras de queijos foram cortadas em $20 \mathrm{~mm}^{3}$, mantidas em BOD (LimaTec LT 320) a $7{ }^{\circ} \mathrm{C}$ e retiradas apenas no momento das análises. Os parâmetros definidos para esta análise foram perfil de textura com velocidade pré-teste: $20 \mathrm{~mm} / \mathrm{s}$; velocidade de teste: $1,0 \mathrm{~mm} / \mathrm{s}$; velocidade de pós-teste: 4,5 $\mathrm{mm} / \mathrm{s}$; distancia de compressão: $9 \mathrm{~mm}$; força de gatilho (trigger): 4,0 g; e probe (sonda) tipo cilindro em acrílico claro de $38,1 \mathrm{~mm}$ de diâmetro. $\mathrm{O}$ texturômetro trabalhou conectado ao computador e os dados coletados foram processados e apresentados pelo programa "TexturePro CT". As determinações foram realizadas em quintuplicata e os atributos analisados foram: dureza, adesividade, coesividade, elasticidade, gomosidade e mastigabilidade. Os resultados obtidos foram utilizados para construção de tabela, apresentando variáveis em função do tempo de armazenagem dos queijos Mussarela.

\section{Análise estatística}

A análise de variância (ANOVA) foi utilizada para determinar o efeito do tempo de maturação sobre as variáveis de resposta de queijos mantidos sob refrigeração e as médias comparadas pelo teste de Tukey a 5\% de significância analisados em intervalos regulares de 20 dias durante o armazenamento, utilizando o programa estatístico R (R Development Core Team, 2011).

\section{RESULTADOS E DISCUSSÃO}

Os resultados dos ensaios microbiológicos referentes a coliformes totais e coliformes termotolerantes estão apresentados na Tabela 1. Estes revelaram eficiência na qualidade higiênico-sanitária durante todo processo de produção dos queijos.

As análises microbiológicas para coliformes totais e termotolerantes demonstraram que a fabricação dos queijos Mussarela está de acordo com os Padrões Microbiológicos vigentes, da Resolução RDC n ${ }^{\circ} 12$ da Agência Nacional de Vigilância Sanitária (ANVISA), a qual preconiza que os queijos de alta umidade 
(46 a 55\%) devem apresentar tolerância máxima para amostras indicativas de $10^{4} \mathrm{NMP} / \mathrm{g}$ para coliformes a $35^{\circ} \mathrm{C}$ e $5 \times 10^{3} \mathrm{NMP} / \mathrm{g}$ para coliformes a $45^{\circ} \mathrm{C}$ (BRASIL, 2001).

Tabela 1 - Valores médios da qualidade microbiológica, quanto à coliformes totais e termotolerantes de queijo Mussarela armazenado durante 60 dias, sob refrigeração a $7{ }^{\circ} \mathrm{C}$

\begin{tabular}{ccc}
\hline \multirow{2}{*}{ Dias } & \multicolumn{2}{c}{ Coliformes $(\mathrm{NMP} / \mathrm{g})^{*}$} \\
\cline { 2 - 3 } & Totais & Termotolerantes \\
\hline 0 & 33,2 & 30,1 \\
20 & 5,7 & 3,1 \\
40 & 3,0 & 3,0 \\
60 & 7,6 & 4,5 \\
\hline
\end{tabular}

*NMP: Número Mais Provável.

Os queijos têm alto valor nutricional, o que favorece a proliferação de microrganismos, que podem levar a alterações nas características do produto (MARINHEIRO et al., 2015). A estocagem por períodos longos pode afetar negativamente a qualidade dos queijos. O desenvolvimento de psicrotróficos totais e proteolíticos consegue alterar as propriedades dos queijos ao longo da vida útil. Na Tabela 2 está apresentada a contagem de microrganismos psicrotróficos e psicrotróficos proteolíticos expressos em log UFC/g.

A deterioração em queijos Mussarela é frequentemente causada por bactérias psicrotróficas proteolíticas (BARUZZI et al., 2012). No entanto, os resultados da contagem de microrganismos psicrotróficos totais e psicrotróficos proteolíticos do presente trabalho não sofreram efeito significativo em função dos dias de armazenamento ( $p$ $>0,05)$. O maior valor encontrado para psicrotróficos totais foi de $2,75 \times 10^{3} \mathrm{UFC} / \mathrm{g}$ e para psicrotróficos proteolíticos foi de $9,12 \times 10^{3} \mathrm{UFC} / \mathrm{g}$. Pinto et al. (2006) sugerem que produtos lácteos devem apresentar contagem menor que $10^{5} \mathrm{UFC} / \mathrm{g}$ com relação a microrganismos psicrotróficos totais e psicrotróficos proteolíticos. A baixa contagem justifica-se pela boa qualidade da matéria prima, eficiência na etapa de pasteurização e a aplicação do regulamento de Boas Práticas de Fabricação em toda linha de produção.

Tabela 2 - Contagem de microrganismos psicrotróficos totais e proteolíticos de queijo Mussarela armazenado durante 60 dias, sob refrigeração a $7{ }^{\circ} \mathrm{C}$

\begin{tabular}{ccc}
\hline \multirow{2}{*}{ Dias } & \multicolumn{2}{c}{${\text { Psicrotróficos }(\log \mathrm{UFC} / \mathrm{g})^{1}}^{1}$} \\
\cline { 2 - 3 } & Totais $^{2}$ & Proteolíticos $^{2}$ \\
\hline 0 & $3,28^{\mathrm{a}}$ & $3,32^{\mathrm{a}}$ \\
20 & $2,83^{\mathrm{a}}$ & $3,11^{\mathrm{a}}$ \\
40 & $3,18^{\mathrm{a}}$ & $3,69^{\mathrm{a}}$ \\
60 & $3,44^{\mathrm{a}}$ & $3,96^{\mathrm{a}}$ \\
\hline
\end{tabular}

${ }^{1} \mathrm{UFC}=$ Unidade Formadora de Colônia; ${ }^{2}$ Médias seguidas pela mesma letra minúscula na mesma coluna não diferem entre si pelo teste de Tukey a $5 \%$ de probabilidade

O efeito do tempo de armazenamento sobre as propriedades físico-químicas de queijo Mussarela estão listados na Tabela 3. Um decréscimo nos valores de $\mathrm{pH}$ do queijo foi observado com o aumento do tempo de armazenamento, apresentando diferença significativa entre os dias 20 e 60 devido a produção de ácido lático. Estudos apontam diminuição do $\mathrm{pH}$ com o aumento do período de armazenamento de queijo Mussarela (YAZICI; AKBULUT, 2007; OLIVARES et al., 2012). Os valores de acidez titulável nas amostras de queijo não apresentaram diferença estatística $(\mathrm{p}<0,05)$, o que pode ser justificado pela cultura láctea utilizada ser composta por Streptococcus thermophilus, que apresenta baixa intensidade na produção de ácido durante o armazenamento (HASSAN; FRANK, 2001), mantendo a acidez titulável próxima de $0,17 \mathrm{~g}$ ácido lático/100 g. 
O queijo Mussarela analisado apresentou valores para umidade variando de 47,03 a 47,24 g/100 g, sendo assim classificado como queijo de alta umidade (46 - 54,9\%) conforme o Regulamento Técnico de Identidade e Qualidade dos Queijos (BRASIL, 1996). O conteúdo de umidade da Mussarela mantevese constante durante os dias de análise, devido ao método de embalagem à vácuo, pois funciona principalmente como barreira a gás, além da baixa permeabilidade ao vapor d'água. Olivares et al. (2012), avaliando o armazenamento de queijo Mussarela em embalagem à vácuo, também não observaram diferença significativa durante 57 dias de armazenamento, com média de 49,63 g/100 $\mathrm{g}$ de umidade.

O teor de cinzas, cloretos, gordura e gordura no extrato seco não sofreram influência significativa do tempo de armazenamento ( $\mathrm{p}>0,05)$. As amostras analisadas apresentaram teores de cloretos variando de 1,25 a 1,46g/100 g, apresentando-se dentro dos valores estabelecidos por Perry (2004), que afirma que os queijos devem apresentar em sua maioria de 0,5 a 2,0g/100 g de $\mathrm{NaCl}$. A adição excessiva de sódio nos alimentos causa hipertensão arterial e a maior parte do sódio na dieta deriva de alimentos processados, principalmente na forma de cloreto de sódio (KHETRA et al., 2015). Entretanto, o cloreto de sódio no alimento é capaz de proporcionar o sabor, auxiliar no controle microbiológico e no aumento do shelflife do produto acabado.

A gordura e agordura no extrato seco dependem principalmente da padronização da matéria prima. Conforme a Portaria ${ }^{\circ} 146 \mathrm{de}$ 1996 (BRASIL, 1996), o queijo Mussarela do presente trabalho é classificado como queijo semigordo por apresentar teor de gordura no extrato seco entre $25,0 \%$ a $44,9 \%$, o que é característico da maioria dos queijos Mussarela. De acordo com Portaria $n^{\circ} 364$, de 04 de setembro de 1997, do Ministério da Agricultura Pecuária e Abastecimento o conteúdo mínimo de gordura no extrato seco de queijos Mussarela deve ser de $35 \mathrm{~g} / 100 \mathrm{~g}$ (BRASIL, 1997), sendo assim, os queijos analisados

Tabela 3 - Composição físico-química de queijo Mussarela armazenado durante 60 dias, sob refrigeração a $7^{\circ} \mathrm{C}$

\begin{tabular}{|c|c|c|c|c|c|}
\hline \multirow[b]{2}{*}{ Parâmetros } & \multicolumn{4}{|c|}{ Período de estocagem (dias) } & \multirow{2}{*}{$\mathrm{CV} \%{ }^{2}$} \\
\hline & $0^{1}$ & $20^{1}$ & $40^{1}$ & $60^{1}$ & \\
\hline $\mathrm{pH}$ & $5,60^{\mathrm{ab}} \pm 0,10$ & $5,61^{a} \pm 0,08$ & $5,58^{\mathrm{ab}} \pm 0,12$ & $5,52^{b} \pm 0,16$ & 2,11 \\
\hline $\mathrm{AT}^{3}(\mathrm{~g} / 100 \mathrm{~g})$ & $0,17^{\mathrm{a}} \pm 0,05$ & $0,17^{\mathrm{a}} \pm 0,03$ & $0,18^{a} \pm 0,06$ & $0,17^{\mathrm{a}} \pm 0,07$ & 32,14 \\
\hline Umidade $(\mathrm{g} / 100 \mathrm{~g})$ & $47,03^{a} \pm 0,66$ & $47,21^{\mathrm{a}} \pm 0,69$ & $47,04^{\mathrm{a}} \pm 1,85$ & $47,24^{\mathrm{a}} \pm 0,79$ & 2,11 \\
\hline Cinzas $(\mathrm{g} / 100 \mathrm{~g})$ & $3,90^{\mathrm{a}} \pm 0,25$ & $3,95^{\mathrm{a}} \pm 0,34$ & $3,96^{\mathrm{a}} \pm 0,12$ & $3,94^{\mathrm{a}} \pm 0,18$ & 6,02 \\
\hline Cloretos (g/100 g) & $1,25^{\mathrm{a}} \pm 0,28$ & $1,46^{\mathrm{a}} \pm 0,10$ & $1,37^{\mathrm{a}} \pm 0,05$ & $1,40^{\mathrm{a}} \pm 0,12$ & 11,67 \\
\hline Gordura (g/100 g) & $20,76^{\mathrm{a}} \pm 1,65$ & $20,15^{\mathrm{a}} \pm 1,85$ & $20,14^{\mathrm{a}} \pm 1,07$ & $20,79^{\mathrm{a}} \pm 1,02$ & 7,06 \\
\hline $\operatorname{GES}^{4}(\mathrm{~g} / 100 \mathrm{~g})$ & $39,19^{\mathrm{a}} \pm 2,88$ & $38,17^{\mathrm{a}} \pm 3,42$ & $38,03^{a} \pm 2,46$ & $39,40^{\mathrm{a}} \pm 2,08$ & 7,11 \\
\hline Proteína $(\mathrm{g} / 100 \mathrm{~g})$ & $27,54^{\mathrm{a}} \pm 1,37$ & $27,53^{\mathrm{a}} \pm 1,37$ & $27,57^{\mathrm{a}} \pm 0,93$ & $27.35^{\mathrm{a}} \pm 3,11$ & 6,87 \\
\hline IEP5 (\%) & $0,22^{\mathrm{c}} \pm 0,11$ & $0,27^{\mathrm{bc}} \pm 0,08$ & $0,29^{\mathrm{b}} \pm 0,08$ & $0,67^{\mathrm{a}} \pm 0,14$ & 29,24 \\
\hline IPP6 (\%) & $0,06^{\mathrm{b}} \pm 0,06$ & $0,03^{\mathrm{b}} \pm 0,03$ & $0,03^{\mathrm{b}} \pm 0,03$ & $0,35^{\mathrm{a}} \pm 0,10$ & 48,77 \\
\hline
\end{tabular}

${ }^{1}$ Médias seguidas pela mesma letra minúscula na mesma linha não diferem entre si pelo teste de Tukey a $5 \%$ de probabilidade; ${ }^{2} \mathrm{CV}=$ Coeficiente de variação; ${ }^{3} \mathrm{AT}=$ Acidez titulável; ${ }^{4} \mathrm{GES}=$ Gordura no Extrato Seco; ${ }^{5}$ IEP: Índice de Extensão Proteolítica; ${ }^{6} \mathrm{IPP}$ : Índice de Profundidade Proteolítica. 
encontram-se dentro do estabelecido pela legislação vigente.

Os valores de proteína não apresentaram diferença significativa $(\mathrm{p}<0,05)$, porém o $60^{\circ}$ dia comparado com o primeiro dia de análise de armazenamento apresentou uma pequena queda no teor de proteína. O principal motivo é o fato da cultura utilizada na produção dos queijos Mussarela (Streptococcus thermophilus) ser pouco proteolítica, assim o tempo de armazenamento não foi suficiente para gerar alteração significativa nos níveis de proteína.

A média do índice de extensão proteolítica (IEP) aumentou significativamente $(\mathrm{p}<0,05)$ com o tempo de armazenamento refrigerado, variando de $0,22 \%$ para $0,67 \%$ respectivamente (Tabela 3 ). Ubaldo et al. (2015) também observaram aumento significativo com o tempo de armazenamento de 60 dias, variando de $6,96 \%$ para $12,32 \%$. Com o passar dos dias, a hidrólise pode continuar aumentando, visto que o estudo apresentou valores menores que os descritos na literatura, as alterações nas suas características funcionais e sensoriais também serão menores.

O teor de nitrogênio solúvel em $\mathrm{pH}$ 4,6 é utilizado rotineiramente como um índice do grau de proteólise primária e sua formação se dá por diferentes origens: plasmina, a qual é derivada a partir de leite, pepsina e quimosina residual no queijo, sobre a $\alpha_{\mathrm{s} 1}$-caseína e, em menor quantidade $\beta$-caseína dando origem a peptídeos de alto e médio peso molecular (FOX, 1989). A presença de enzimas proteolíticas provenientes de microrganismos que hidrolisam os peptídeos resultantes da ação do coalho e da plasmina está relacionada ao índice de profundidade da proteólise em queijo Mussarela (FOX, 1989). O presente estudo apontou que no decurso de 60 dias de armazenamento o índice de profundidade proteolítica (IPP) passou de $0,06 \%$ a $0,35 \%$, sendo o nível mais elevado estatisticamente no último dia de análise, proveniente do acúmulo de aminoácidos livres.
Os níveis de extensão e profundidade proteolítica em queijos Mussarela produzidos com diferentes contagens de células somáticas utilizando cultura starter (TCC-20 - Streptococcus salivarius ssp. Thermophilus e Lactobacillus helveticus) também apresentaram aumento significativo $(\mathrm{p}<0,05)$ no tempo de armazenamento de 60 dias, variando de $6,96 \%$ a $12,32 \%$ para IEP e $3,38 \%$ a $6,71 \%$ para IPP (UBALDO et al., 2015). Os valores encontrados neste estudo para os índices de proteólises são menores que os descritos literatura, pois a indústria em estudo utiliza apenas Streptococcus thermophilus confirmando que as alterações do queijo foram pequenas durante o armazenamento quando comparados com os demais estudos.

O queijo Mussarela é usado principalmente em pizzas e alimentos relacionados, e deve possuir propriedades funcionais específicas, quanto submetido ou não ao aquecimento. As características funcionais do queijo Mussarela estão apresentadas na Tabela 4. A capacidade de derretimento do queijo Mussarela evoluiu significativamente ao longo da estocagem passando de $9,62 \%$ para $12,16 \%$. Esse aumento está relacionado proporcionalmente com o incremento do índice de extensão da proteólise durante o armazenamento. A hidrólise das proteínas enfraquece a matriz proteica, o que faz com que o queijo perca a capacidade de manter sua estrutura durante o aquecimento, assim o derretimento tende a ser maior quando a degradação das proteínas aumenta (ROIG et al., 2003).

As mudanças ocorridas durante a armazenagem não foram significativas $(\mathrm{p}>0,05)$ em relação à proporção de óleo livre. Rowney et al. (2004) mostraram valores de óleo livre variando de $3,0 \%$ a $3,6 \%$ utilizando diferentes temperaturas de salmoura. A liberação de óleo está relacionada com a integridade da matriz proteica e com o teor de gordura do queijo, pois quanto mais maturado o queijo, 
maior será a liberação de óleo livre (CHIESA et al., 2011).

Os parâmetros de cor do queijo Mussarela apresentados na Tabela 4 alteraram significativamente durante o armazenamento refrigerado. O parâmetro Luminosidade $\left(\mathrm{L}^{*}\right)$ é a relação entre a luz refletida e absorvida, o que faz com que se defina o produto entre a cor preta (totalidade da luz absorvida) e branca (totalidade da luz refletida) (GRANATO; MASSON, 2010). O parâmetro Luminosidade teve diminuição significativa $(\mathrm{p}<0,05)$ quando comparado o primeiro com o último dia de análise. A cor dos queijos apresentou valores com tendência a perda de luminosidade do produto, variando de 60,39 para 53,98 , indicando a tendência de coloração clara dos queijos. Zhong et al. (2014) encontraram em queijo Mussarela valores variando de 76,81 a 57,67 durante 14 dias de armazenamento. Essa diferença entre os trabalhos explica-se uso de revestimentos comestíveis nos queijos elaborados por Zhong et al. (2014). As alterações na coloração do queijo estão relacionadas as mudanças decorrentes da maturação, por esse motivo é notório a diminuição da luminosidade durante o período de armazenamento.

O parâmetro Croma $\left(\mathrm{C}^{*}\right)$ manteve-se constate até o $41^{\circ}$ dia de armazenamento e posteriormente apresentou queda $(\mathrm{p}<0,05)$. Assim como na luminosidade, a maturação do queijo provocada a alteração dos valores de Croma, ocasionando opacidade. O Croma (C*) indica a intensidade ou pureza do tom, independente de quão clara ou escura é a cor. Quanto maior é o seu valor, a cor é mais intensa ou altamente cromática parecendo luminosa ou concentrada, enquanto que valores baixos (acromático) indicam a cor acinzentada, fraca ou diluída (GRANATO; MASSON, 2010). Os valores de Croma do presente trabalho apresentaram-se baixos devido à coloração características do queijo Mussarela. Zhong et al. (2014), avaliando queijo Mussarela, encontraram média de 16,67 para Croma, próximo do descrito no presente estudo, requerido para queijos Mussarela.

O ângulo Hue (ângulo de coloração) identifica cores como vermelho, verde, azul ou amarelo. Inicia no eixo $\left(+\mathrm{a}^{*}\right)$ e é expresso em graus, sendo $0^{\circ}$ para o vermelho, $90^{\circ}$ para o amarelo $\left(+\mathrm{b}^{*}\right), 180^{\circ}$ para verde $\left(-a^{*}\right)$ e $270^{\circ}$ para azul (-b*) (GRANATO; MASSON, 2010). Observa-se que mesmo com as diferenças apresentadas $(\mathrm{p}<0,05)$ entre os dias de armazenamento, os mesmos apresentaram ângulo de tonalidade próximo a $90^{\circ}$, o qual corresponde à coloração ama-

Tabela 4 - Características funcionais de queijo Mussarela armazenado durante 60 dias, sob refrigeração a $7{ }^{\circ} \mathrm{C}$

\begin{tabular}{lccccc}
\hline & \multicolumn{5}{c}{ Período de estocagem (dias) } \\
\cline { 2 - 5 } \multicolumn{1}{c}{ Parâmetros } & $0^{1}$ & $20^{1}$ & $40^{1}$ & $60^{1}$ & CV\% \\
\hline Derretimento (\%) & $9,62^{\mathrm{d}} \pm 0,80$ & $10,32^{\mathrm{c}} \pm 0,77$ & $11,42^{\mathrm{b}} \pm 1,10$ & $12,16^{\mathrm{a}} \pm 0,97$ & 8,47 \\
Óleo livre (\%) & $2,67^{\mathrm{a}} \pm 0,69$ & $2,37^{\mathrm{a}} \pm 0,50$ & $2,54^{\mathrm{a}} \pm 0,98$ & $2,51^{\mathrm{a}} \pm 0,46$ & 27,46 \\
$\mathrm{~L}^{* 3}$ & $60,39^{\mathrm{b}} \pm 4,74$ & $64,12^{\mathrm{a}} \pm 2,70$ & $60,75^{\mathrm{b}} \pm 5,15$ & $53,98^{\mathrm{c}} \pm 3,86$ & 7,05 \\
$\mathrm{C}^{* 4}$ & $18,29^{\mathrm{a}} \pm 1,29$ & $18,71^{\mathrm{a}} \pm 2,22$ & $18,21^{\mathrm{a}} \pm 1,48$ & $16,46^{\mathrm{b}} \pm 1,13$ & 8,83 \\
${ }^{\mathrm{o}} \mathrm{H}^{5}$ & $87,66^{\mathrm{a}} \pm 0,81$ & $86,74^{\mathrm{c}} \pm 0,59$ & $87,35^{\mathrm{b}} \pm 0,52$ & $87,43^{\mathrm{ab}} \pm 0,64$ & 0,74 \\
\hline
\end{tabular}

${ }^{1}$ Médias seguidas pela mesma letra minúscula na mesma linha não diferem entre si pelo teste de Tukey a $5 \%$ de probabilidade; ${ }^{2} \mathrm{CV}=$ Coeficiente de variação; ${ }^{3} \mathrm{~L}^{*}=$ Luminosidades; ${ }^{4} \mathrm{C}^{*}=\mathrm{Croma} ;{ }^{\circ} \mathrm{H}=$ ângulo Hue 
rela. A cor amarelada do queijo provém do pigmento caroteno presente no leite, o qual é um pigmento lipossolúvel. Queijos frescos analisados por Zamora et al. (2011) também apresentaram valores entre $89^{\circ}$ e $94^{\circ}$ para a ângulo Hue.

Na Tabela 5 estão apresentados os dados da análise do perfil de textura de queijos Mussarela durante o armazenamento. Ao longo de 61 dias o queijo Mussarela apresentou diminuição significativa $(\mathrm{p}<0,05)$ na dureza (que é a força necessária para atingir uma dada deformação) de $67,54 \mathrm{~N}$ para $47,43 \mathrm{~N}$, em decorrência do enfraquecimento da matriz proteica do queijo pela ação do coagulante residual e de enzimas de origem microbiana, provocando aumento da proteólise (AYYASH; SHAH, 2011). Queijos avaliados por Zisu; Shah (2005) apresentaram queda em 60 dias de armazenamento, com valores entre $60 \mathrm{~N}$ e $10 \mathrm{~N}$, apresentando maior degradação da matriz proteica quando comparado com o presente estudo.

A adesividade refere-se à força requerida para remover o material que adere à boca durante o processo de mastigação, sendo que aos 20 dias de estocagem houve aumento significativo $(\mathrm{p}<0,05)$ quando comprado aos demais dias. Observação semelhante foi relatada por Wadhwani et al. (2011), que afirmaram que durante o armazenamento a rede de caseína se enfraquece com o aumento da proteólise causada por coagulante residual no queijo, resultando numa textura menos firme e adesiva.

A coesividade é considerada o grau no qual uma substância é comprimida entre os dentes antes de romper, observou-se variação significativa $(\mathrm{p}<0,05)$ deste parâmetro, e nota-se que essa alteração está relacionada com a umidade do queijo, quanto maior foi o teor de umidade menor o valor encontrado para coesividade. De acordo com Zisu; Shah (2005) o aumento da umidade e suavidade dos queijos é responsável pela diminuição da coesividade. Ren et al. (2013) encontraram valores variando de 0,45 a 0,72 em função do genótipo K-caseína, valores próximos aos encontrados neste estudo.

O queijo Mussarela não mostrou redução significativa $(\mathrm{p}>0,05)$ na elasticidade com o passar do tempo, mantendo assim o grau que o queijo volta a sua forma original, depois da compressão com os dentes. A gomosidade, que é definida como a força necessária para desintegrar a massa do queijo, obtida durante a mastigação, até que atinja o ponto de engolir, diminuiu ao longo de 61

Tabela 5 - Perfil de textura de queijo Mussarela armazenado durante 60 dias, sob refrigeração a $7{ }^{\circ} \mathrm{C}$

\begin{tabular}{|c|c|c|c|c|c|}
\hline \multirow[b]{2}{*}{ Parâmetros } & \multicolumn{4}{|c|}{ Período de estocagem (dias) } & \multirow{2}{*}{$\mathrm{CV} \%{ }^{2}$} \\
\hline & $0^{1}$ & $20^{1}$ & $40^{1}$ & $60^{1}$ & \\
\hline Dureza $(\mathrm{N})$ & $67,54^{\mathrm{a}} \pm 15.82$ & $61,32^{b} \pm 12.02$ & $51,16^{\mathrm{c}} \pm 9,75$ & $47,43^{b} \pm 14,42$ & 23,22 \\
\hline Adesividade (mJ) & $2,76^{\mathrm{b}} \pm 0,88$ & $3,47^{\mathrm{a}} \pm 0,10$ & $2,96^{\mathrm{b}} \pm 0,90$ & $2,73^{b} \pm 0,67 b$ & 29,25 \\
\hline Coesividade & $0,61^{\mathrm{a}} \pm 0,04$ & $0,59^{b} \pm 0,03$ & $0,61^{a} \pm 0,03$ & $0,59^{\mathrm{b}} \pm 0,03$ & 5,78 \\
\hline Elasticidade (mm) & $7,09^{\mathrm{a}} \pm 0,69$ & $7.26^{\mathrm{a}} \pm 0,50$ & $7,14^{\mathrm{a}} \pm 0,98$ & $6,81^{\mathrm{a}} \pm 0,46$ & 22,51 \\
\hline Gomosidade (mJ) & $40,73^{a} \pm 1,07$ & $36.27^{b} \pm 2,45$ & $30,93^{\mathrm{c}} \pm 1,49$ & $27,61^{\mathrm{d}} \pm 0,89$ & 21,91 \\
\hline Mastigabilidade (N) & $288,41^{\mathrm{a}} \pm 8,70$ & $265,86^{\mathrm{a}} \pm 7,32$ & $219,27^{b} \pm 5,58$ & $187,46^{\mathrm{c}} \pm 7,74$ & 31,81 \\
\hline
\end{tabular}

${ }^{1}$ Médias seguidas pela mesma letra minúscula na mesma linha não diferem entre si pelo teste de Tukey a $5 \%$ de probabilidade; ${ }^{2} \mathrm{CV}=$ Coeficiente de variação 
dias, passando de $40,73 \mathrm{~N}$ para $27,61 \mathrm{~N}$, assim como a mastigabilidade, a qual apresentou queda significativa de $100,95 \mathrm{~mJ}$ de energia requerida para desintegrar um alimento até o ponto de engolir. Ambas estão relacionadas com a dureza, pois quanto maior a degradação da rede proteica do queijo, menor a dureza e menos força é requerida para mastigar um alimento sólido até a deglutição.

\section{CONCLUSÃo}

Os parâmetros microbiológicos referentes à coliformes totais e termotolerantes estão de acordo com a legislação vigente. A medida que ocorreu o aumento da proteólise primária e secundária, houve também o aumento na capacidade de derretimento mostrando-se adequado para uso em pizzas. Os parâmetros do perfil de textura avaliados foram influenciados pelo tempo de armazenamento, porém as mudanças ocorridas são aceitáveis e requeridas. Desta forma o queijo Mussarela de alta umidade apresentou-se próprio para o consumo com período de armazenamento de 61 dias a $7^{\circ} \mathrm{C}$.

\section{AGRADECIMENTOS}

À Coordenadoria de Aperfeiçoamento de Pessoal de Nível Superior (Capes), pela bolsa de estudo concedida para a execução deste trabalho, e ao Instituto Federal Goiano - Campus Rio Verde por todo o apoio necessário para o desenvolvimento desta pesquisa.

\section{REFERÊNCIAS}

ABNT (ASSOCIAÇÃO BRASILEIRA DE NORMAS TÉCNICAS). Bactérias coliformes totais, coliformes fecais e Escherichia coli em alimentos: determinação do número mais provável (NMP): MB-3463. Rio de Janeiro: ABNT, 1991, 7p.
AOAC (ASSOCIATION OF OFFICIAL ANALYTICAL CHEMISTS). Official methods of analysis of the AOAC International. 19th edition. Washington: AOAC, 2012.

APHA (AMERICAN PUBLIC HEALTH ASSOCIATION). Compendium of methods for the microbiological examination of foods. Washington: APHA, 2001. 676p.

AYYASH, M. M.; SHAH, N. P. The effect of substitution of $\mathrm{NaCl}$ with $\mathrm{KCl}$ on chemical composition and functional properties of low-moisture Mozzarella cheese. Journal of Dairy Science, v. 94, n. 8, p. 3761-3768, 2011 .

BARUZZI, F. et al. Occurrence of non-lactic acid bacteria populations involved in protein hydrolysis of cold-stored high moisture Mozzarella cheese. Food Microbiology, v. 30, n. 1, p. 37-44, 2012.

BRASIL. Ministério da Agricultura, Pecuária e Abastecimento. Portaria $n^{\circ} 146$, de 07 de março de 1996. Aprova o Regulamento Técnico de Identidade e Qualidade dos Queijos. Diário Oficial da República Federativa do Brasil, Brasília, 11 de março de 1996.

BRASIL. Ministério da Agricultura, Pecuária e Abastecimento. Portaria $n^{\circ} 364$, de 04 de setembro de 1997. Aprova o Regulamento Técnico para Fixação de Identidade e Qualidade de Queijo Mozzarella (Muzzarella ou Mussarela). Diário Oficial da República Federativa do Brasil, Brasília, 04 de setembro de 1997.

BRASIL. Ministério da Saúde. Agência Nacional de Vigilância Sanitária. Instrução Normativa $n^{\circ} 68$, de 12 de 2006. Oficializa os Métodos Analíticos Oficiais Físico-Químicos, 
para Controle de Leite e Produtos Lácteos, Diário Oficial da República Federativa do Brasil, Brasília, 14 de dezembro de 2006.

BRASIL. Ministério da Saúde. Agência Nacional de Vigilância Sanitária. Resolução RDC n ${ }^{\circ} 12$, de 2 de janeiro de 2001. Aprova o Regulamento técnico sobre os padrões microbiológicos para alimentos. Diário Oficial da República Federativa do Brasil, Brasília, 10 de janeiro de 2001.

CANTONI, C. et al. Colorazioni anomale e rigonfiamento di formaggi fusi e mozzarelle. Industrie Alimentari, v. 45, p. 276-281, 2006 .

CHIESA, M. O. et al. Avaliação da composição química, proteólise e propriedades funcionais do queijo Mussarela comercial com teor reduzido de gordura. Revista do Instituto de Laticínios Cândido Tostes, v. 66, n. 381, p. 28-33, 2011.

FOX, P. F. Proteolysis during cheese manufacture and ripening. Journal of Dairy Science, v. 72, n. 6, p. 1379-1400, 1989.

GARCIA, E. F. et al. Development and quality of a Brazilian semi-hard goat cheese (coalho) with added probiotic lactic acid bacteria. International Journal of Food Science and Nutrition, v. 63, n. 8, p. 947-956, 2012.

GRANATO, D.; MASSON, M. L. Instrumental color and sensory acceptance of soy-based emulsions:a response surface approach. Ciência e Tecnologia de Alimentos, v. 30, n. 4, p. 1090-1096, 2010.

HASSAN, A. N.; FRANK, J. F. Starter culturesandtheir use. In: MARTH, E. H.; STEELE, J. L. Applied Dairy Microbiology. New York: Marcel Decker, 2001.
JONGHE, V. et al. Influence of storage conditions on the growth of Pseudomonas species in refrigerated raw milk. Applied and Environmental Microbiology, v. 77, n. 2, p. 460-470, 2011.

KHETRA, Y. et al. Storage changes in low sodium-processed Mozzarella cheese prepared using potassium-based emulsifying salts. Dairy Science \& Technology, v. 95, n. 5, p. 639-649, 2015.

KINDSTEDT, P. S.; FOX, P. F. Effect of manufacturing factors, composition and proteolysis on the functional characteristics of mozzarella cheese. Critical Reviews in Food Science and Nutrition, v. 33, n. 2, p. 167-187, 1993.

KINDSTEDT, P. S.; FOX, P. F. Modified Gerber test for free oil in melted Mozzarella cheese. Journal of Food Science, v. 56, n. 4, p. 1115-1116, 1991 .

KOSIKOWSKI, F.; MISTRY, V. V. Cheese and fermented milk foods. Michigan: Edwards Brothers, 1997. 323p.

MARINHEIRO, M. F. et al. Qualidade microbiológica de queijo Mussarelaem peça e fatiado. Semina: CiênciasAgrárias, v. 36, n. 3, p. 1329-1334, 2015.

MARSHALL, R. T. Standard Methods for the Examination of Dairy Products. 16th ed. APHA: Washington, D.C. 1992.

OLIVARES, M. L. et al. Effect of protective atmospheres on physicochemical, microbiological and rheological characteristics of sliced Mozzarella cheese. LWT - Food Science and Technology, v. 47, n. 2, p. 465470, 2012.

OLIVEIRA, M. B. Avaliação de queijos 
ricota comercializados em Goiânia-GO e queijos processados com diferentes concentrações de leite e adicionados de proteínas de soja e cálcio. 2012. 109 f. Dissertação (Mestrado em Ciência e Tecnologia de Alimentos) - Universidade Federal de Goiás, 2012.

PAULA, J. C. J. de. et al. Princípios básicos de fabricação de queijo: do histórico à salga. Revista do Instituto de Laticínios Cândido Tostes, v. 64, n. 367/368, p. 19-25, 2009.

PERRY, K. S. P. Queijos: aspectos químicos, bioquímicos e microbiológicos. Química Nova, v. 27, n. 2, p. 293-300, 2004.

PIAZZON-GOMES, J. et al. Queijo tipo minas frescal com derivados de soja: características físicas, químicas e sensoriais. Ciência e Tecnologia de Alimentos, v. 30, supl. 1, p. 77-85, 2010.

PINTO, C. J. O. et al. Qualidade microbiológica de leite cru refrigerado e isolamento de bactérias psicrotróficas proteolíticas. Ciência e Tecnologia de Alimentos, v. 26, n. 3, p. 645-651, 2006.

R Development Core Team. R: A language and environment for statistical computing. Vienna, Austria: R Foundation for Statistical Computing, 2011. Disponível em: http://www.R-project.org. Acesso em: 21 set 2018 .

REN, D. et al. The effects of k-casein polymorphism on the texture and functional properties of mozzarella cheese. International Dairy Journal, v. 31, n. 2, p. 65-69, 2013.

RICCIARDI, A. et al. Evolution of microbial counts and chemical and physico-chemical parameters in high-moisture Mozzarella cheese during refrigerated storage. LWT -
Food Science and Technology, v. 63, n. 2, p. 821-827, 2015.

ROIG, S. M. et al. Avaliação da proteólise e do derretimento do queijo Prato obtido por ultrafiltração. Ciência e Tecnologia de Alimentos, v. 23, supl., p. 177-182, 2003.

ROWNEY, M. K. et al. Salt-induced structural changes in 1-day old Mozzarella cheese and the impact upon free oil formation. International Dairy Journal, v. 14, n. 9, p. 809-816, 2004.

SANTOS, P. A. Avaliação do leite cru refrigerado produzido na região sudoeste do estado de Goiás estocado por diferentes períodos. 2008. 61 p. Tese (Doutorado em Ciência Animal) - Universidade Federal de Goiás, 2008.

STEELE, J. et al. Perspectives on the contribution of lactic acid bacteria to cheese flavor development. Current Opinion in Biotechnology, v. 24, n. 2, p. 135-141, 2013.

UBALDO, J. C. S. R. et al. Bioactive amines in Mozzarella cheese from milk with varying somatic cell counts. Food Chemistry, v. 178, n. 1, p. 229-235, 2015.

WADHWANI, R. et al. Improvement in melting and baking properties of lowfat Mozzarella cheese. Journal of Dairy Science,v. 94, n. 4, p. 1713-1723, 2011.

WOLF, I. V. et al. Study of the chemical composition, proteolysis, lipolysis and volatile compounds profile of commercial Reggianito Argentino cheese: Characterization of Reggianito Argentino cheese. Food Research International, v. 43, n. 4, p. 12041211, 2010.

YAZICI, F.; AKBULUT, C. Impact of whey pH 
at drainage on the physicochemical, sensory, and functional properties of Mozzarella cheese made from buffalo milk. Journal Agricultural and Food Chemistry, v. 55, n. 24, p. 9993-10000, 2007.

ZAMORA, A. et al. Effect of ultrahigh pressure homogenization of Milk on the texture and water-typology of a starter-free fresh cheese. Innovative Food Science and Emerging Technologies, v. 12, n. 4, p. 484490, 2011.
ZHONG, T. et al. Investigation of different coating application methods on the performance of edible coatings on Mozzarella cheese. LWT - Food Science and Technology, v. 56, n. 1, p. 1-8, 2014.

ZISU, B.; SHAH, N. P. Textural and functional changes in low-fat Mozzarella cheeses in relation to proteolysis and microstructure as influenced by the use of fat replacers, pre-acidification and EPS starter. International Dairy Journal, v. 15, n. 6-9, p. 957972, 2005. 